AÑEZ, María Alejandra; LEONTE, Pablo. "La política criminal en Venezuela. Especial referencia a la conflictividad social en torno al delito de secuestro".

Polit. crim. Vol. 6, № 11 (Junio 2011), Art. 2, pp. 19 - 43.

[http://www.politicacriminal.cl/Vol_06/n_11/Vol6N11A2.pdf]

\title{
La política criminal en Venezuela. Especial referencia a la conflictividad social en torno al delito de secuestro. ${ }^{*}$
}

\author{
MgSc. María Alejandra Añez Castillo ** \\ Dr. Pablo Leonte Han Chen ***
}

\section{Resumen}

La política criminal se concibe como una sección de la política pública destinada a la planificación, ejecución y control de lineamientos preventivos y represivos en la lucha de la criminalidad. Esta investigación de tipo documental-descriptiva reseña como en Venezuela, no se ha formulado una verdadera política criminal, por ello, las respuestas al fenómeno criminal han estado carentes de coherencia y han consistido en respuestas espasmódicas frente a determinados sucesos y la política antisecuestro no escapa a esta realidad. No existe una política ni estrategia clara y a largo plazo respecto del secuestro, no se conoce la magnitud del sistema de información nacional, la falta de coordinación entre los cuerpos de seguridad, la disputa entre los diversos organismos competentes, son algunos de las barreras con las cuales se enfrentan el Estado y a la vez constituye una ventaja para la delincuencia común y organizada. La superación de los obstáculos empieza por mostrar una verdadera voluntad política; generando acciones concretas, certeras, planificadas y pertinentes en torno a las políticas públicas gubernamentales en todas sus aristas, sin exclusiva referencia al sistema penal.

\section{Palabras clave}

Secuestro, política criminal, combate contra el secuestro.

\begin{abstract}
Criminal policies are conceived as a section of public policies destined to the planning, execution and control of preventive and repressive limits in the fight against criminality. This documentary-descriptive investigation outlines how in Venezuela, real criminal policies have not been formulated. For this reason, the answers to the criminal phenomenon have been lacking in coherence and have consisted of spasmodic answers to certain events and the anti-kidnapping policy does not escape this reality. Neither a policy nor a clear long-term strategy regarding kidnapping exist, the magnitude of the national information system is unknown, the lack of coordination between the security

\footnotetext{
* Este artículo es producto del Proyecto de Investigación "Anatomía del Secuestro en Venezuela", registrado ante el Consejo de Desarrollo Científico, Humanístico y Tecnológico (CONDES) de la Universidad del Zulia, bajo el oficio de aprobación VAC-CONDES-CH-0039 de fecha 17-02-2010.

** Profesora Agregada e Investigadora del Instituto de Criminología Dra. Lolita Aniyar de Castro de la Facultad de Ciencias Jurídicas y Políticas de la Universidad del Zulia. Venezuela. Correo Electrónico: maac2504@hotmail.com

*** Profesor Titular e Investigador del Instituto de Criminología Dra. Lolita Aniyar de Castro de la Facultad de Ciencias Jurídicas y Políticas de la Universidad del Zulia. Venezuela. Correo Electrónico: pablohan@hotmail.com
} 
AÑEZ, María Alejandra; LEONTE, Pablo. "La política criminal en Venezuela. Especial referencia a la conflictividad social en torno al delito de secuestro".

agencies, the dispute between the different competent organisms, these are some of the barriers faced by the State and which simultaneously are an advantage for both common and organized crime. Overcoming these obstacles begins by showing true political will; generating concrete, accurate, planned and pertinent actions concerning public governmental policies in all their aspects, without sole reference to the penal system.

\section{Key words}

Kidnapping, criminal policies, fight against kidnapping.

\section{Introducción.}

La inseguridad en Venezuela, ha pasado de ser un sentimiento a una realidad innegable, y dentro de ella el secuestro es uno de los delitos que repuntan en las noticias que a diario relatan los medios de comunicación, con un alto costo social, dada la complejidad de situaciones y personas que involucra.

De acuerdo a las estadísticas oficiales publicadas por el Instituto Nacional de Estadísticas (INE) en el año 1999 se registran 44 casos de secuestro, lo que representa una tasa de 5.15 por cada 100.000 habitantes, mientras que en el 2006 se registraron 232 casos equivalentes a una tasa de 20.74 por cada 100.000 habitantes.

El año 2009 terminó con una cifra sin precedentes en cuanto a los secuestros reportados en todo el país. Datos aportados por la reciente Encuesta Nacional de Victimización y Percepción de Seguridad Ciudadana 2009 (INE, 2010), computan una alarmante cifra de 16.917 casos reportados en ese período.

Es evidente, que los cambios sociales han impulsado a su vez, las modificaciones en el ordenamiento jurídico penal; el legislador, de acuerdo a la realidad de sus tiempos, ha procurado combatir ese delito con la mayor severidad punitiva, y así se evidencia en las diversas reformas al Código Penal desde 1897 -cuando se establece por primera vez como delito autónomo- hasta el vigente del año 2005, de cuyo artículo 460 se desprende la gravedad de este delito en la sociedad venezolana; el cual es llevado a su máxima expresión el 5 de junio de 2009, con la publicación en la Gaceta Oficial No. 39.194 de la Ley contra el Secuestro y la Extorsión, como instrumento legal regulador de este delito en Venezuela.

La realidad social, jurídica, política y económica que aborda a Venezuela, y el acelerado incremento delictivo en el país, asoma una necesidad de cambio, el establecimiento de cursos de acción a largo plazo que plasmen soluciones efectivas y apuesten por una mejor calidad de vida para el ciudadano. Indudablemente, ello requiere de un diagnostico previo, pues existen en el panorama numerosas inquietudes y expectativas ante la resolución del problema. Por este motivo, este trabajo se ha planteado como objetivo identificar la política criminal en Venezuela, con especial referencia al delito de secuestro y su viabilidad para combatir esta modalidad delictiva en el país. 
Polit. crim. Vol. 6, № 11 (Junio 2011), Art. 2, pp. 19 - 43.

[http://www.politicacriminal.cl/Vol_06/n_11/Vol6N11A2.pdf]

\section{Definición de Política Criminal.}

La política criminal, como se conoce hoy, tiene sus orígenes a finales del siglo XIX (1803) con el alemán Fran Von Liszt quien la definió como "el conjunto sistemático de principios, con arreglo a los cuales deben organizar el Estado y la sociedad la lucha contra el crimen".

Por su parte, Gabaldón, ${ }^{2}$ entiende por política criminal todas las actividades dirigidas o coordinadas por el Estado para identificar la problemática delictiva y para adoptar medidas tendentes a minimizar los efectos de la criminalidad. En otras palabras, se trata de la formulación de políticas públicas para el control de la criminalidad por parte del Estado.

Partiendo de esta idea, planear el sistema de justicia penal, no supone únicamente un marco normativo en función de cifras, tiene que ver además con calidad de vida, se apoya en la educación, la salud, la nutrición, el trabajo, la vivienda, el salario, la recreación, entre otros, es muchos más que la policía, los tribunales y las cárceles; se trata de investigar, juzgar y sancionar, pero también de desarrollar al pueblo. En este sentido, la política criminal debe ser considerada como una sección de la política social del Estado. ${ }^{3}$ Por ello, el enfrentamiento de los índices de criminalidad, se asume como una política integral, que comprende, por una parte, la reducción de las desigualdades sociales, el incremento del nivel de empleo y la atención a los grupos sociales relativamente pobres y, por la otra, una política específica para la prevención y combate de la criminalidad y la violencia. ${ }^{4}$

A los efectos de esta investigación se ha conceptualizado la política criminal, como una sección de la política pública destinada a la planificación, ejecución y control de lineamientos preventivos y represivos en la lucha de la criminalidad en Venezuela.

\section{Orientación de la Política Criminal Venezolana.}

Dentro del sistema venezolano, la política criminal ha de ser considerada como aquella política pública que debe desarrollar de manera permanente y sistemática el Estado, como una función de gobierno, que tenga como objeto la formación de planes y el desarrollo de programas estratégicos, dirigidos a controlar y minimizar la criminalidad, valiéndose para ello de todos los instrumentos legales operativos, institucionales, sociales y de participación ciudadana, que por ser pertinentes, le permitan prevenir,

\footnotetext{
${ }^{1}$ BERISTAIN, Antonio, "Hoy y Mañana de la Política Criminal. Protectora y Promotora de los Valores Humanos". En: Politica Criminal Comparada, Hoy y Mañana. Compilado por BERISTAIN, Antonio, Cuadernos de Derecho Judicial, Consejo General del Poder Judicial, Escuela Judicial. Madrid, España, 2009. pp. 11-85, pp.14-15.

${ }^{2}$ GABALDON, Luis Gerardo, "Criminalidad, Reacción Social y Política: Una Visión en el Contexto de la Reforma Policial Venezolana”, Revista Relación Criminológica, Universidad de Carabobo, Segunda Etapa, No. 15, Segundo Semestre (2006), pp. 67-78.

${ }^{3}$ GARCÍA, Sergio, "Reflexiones de Política Criminal", Criminalia. México, Año LXII, No. 2 (1997), pp. 93-101. En http://www.bibliojuridica.org/libros/2/756/22.pdf [visitado el 01-12-2009].

${ }^{4}$ NUÑEZ, Gilda, "Política de Seguridad Ciudadana en Venezuela. Especial Referencia al Desarrollo Jurídico Penal.”, Capitulo Criminológico, Volumen 34, No. 3 (2004), Instituto de Criminología Dra. Lolita Aniyar de Castro. Universidad del Zulia, Maracaibo, Venezuela, pp. 339-361.
} 
AÑEZ, María Alejandra; LEONTE, Pablo. "La política criminal en Venezuela. Especial referencia a la conflictividad social en torno al delito de secuestro".

criminalizar, perseguir y sancionar a los agentes del delito, de acuerdo con su grado de responsabilidad penal. ${ }^{5}$

Muchos expertos coinciden en el hecho de que en Venezuela, desde el advenimiento de la democracia a finales del siglo pasado, no se ha formulado una verdadera política criminal para la democracia, por ello, las respuestas al fenómeno criminal han estado carentes de coherencia y han consistido en respuestas espasmódicas frente a determinados sucesos, ante los cuales se ha respondido predominantemente con la hipertrofia del derecho penal, tomado como única propuesta de acuerdo a cómo se percibe el fenómeno criminal, llevándose a cabo reformas a las leyes penales $o$ procesales, aisladas del conjunto del sistema, es decir, del proceso, de la ejecución de la pena y de la prevención. ${ }^{6}$

En efecto, una mirada a la evolución de la política antidelictiva en Venezuela, se orienta fundamentalmente en tono represivo, aun cuando abundante doctrina sostiene en la actualidad que la pena no contiene un fin realizable como instrumento principal hacia la prevención de la criminalidad. Además, los recursos legislativos utilizados hasta ahora se amparan en la satisfacción de demandas sociales y políticas de seguridad y orden, propiciando respuestas penales contingentes, caracterizándose por ser leyes reactivas que de ningún modo pueden ser eficientes para la prevención y combate de la delincuencia. ${ }^{7}$

Esto entre otros factores por el inexacto conocimiento de la magnitud del problema, la incorrecta distribución de los recursos humanos, materiales y financieros a nivel nacional, la falta de continuidad en los planes por el continuo reemplazo de ministerios y consecuentemente de directores de despacho y la falta de evaluación y seguimiento de las políticas públicas establecidas, todo lo cual desemboca en la carencia de una visión consistente y estable sobre prevención, permaneciendo inalterado el desinterés con que el Estado venezolano ha manejado esta área de la política antidelictiva a lo largo de los años. ${ }^{8}$

\subsection{La Política Criminal durante 40 años de Periodo Democrático (1958 - 1998).}

En 1958, mediante decreto No. 492 del 30 de diciembre de 1958, se crea la Oficina Central de Coordinación y Planificación de la Presidencia de la República (CORDIPLAN), con el objeto de:

"asesorar al Presidente de la República, al Consejo de Ministros y a los demás centros de decisión del Gobierno, en la formulación e instrumentación de la estrategia de desarrollo económico - social del país, promoviendo para tal efecto los planes,

\footnotetext{
5 MARTINEZ, José, "Política Criminal, Terrorismo y Reforma Penal. El Caso Venezuela.", Revista CENIPEC. Centro de Investigaciones Penales y Criminológicas Héctor Febres Cordero, Universidad de Los Andes, Facultad de Ciencias Jurídicas y Políticas, Mérida-Venezuela. Vol. 25 (2006), pp. 326-327.

6 LARRANDART, Lucila, "Política Criminal y Estado de Derecho. ¿Tolerancia Cero?", Capitulo Criminológico, Volumen 34, No. 2 (2006), Instituto de Criminología Dra. Lolita Aniyar de Castro, Universidad del Zulia, Maracaibo-Venezuela, p. 165.

${ }^{7}$ NUÑEZ, "Política de Seguridad Ciudadana", cit. nota n 4, p. 357.

8 BRAVO, Luis, "Obstáculos a la Prevención del Delito en Venezuela". Ponencia presentada en el I Encuentro Anual de Criminología, Universidad de Los Andes, Mérida, Venezuela, 2004. Disponible en http://www.venecrim.com/pdf/OBSTACULOSALAPREVENCIONDELDELITOENVENEZUELA.pdf. [visitado el 12-12-2009].
} 
Polit. crim. Vol. 6, № 11 (Junio 2011), Art. 2, pp. 19 - 43.

[http://www.politicacriminal.cl/Vol_06/n_11/Vol6N11A2.pdf]

políticas y proyectos nacionales compatibles con esta estrategia, facilitando al mismo tiempo la indispensable coordinación entre las organizaciones relevantes para su ejecución"9

No obstante, no es sino hasta el IV Plan de la Nación, correspondiente al quinquenio 1970-1975, cuando se da un modesto lugar al problema del delito y su control, al expresarse:

"El delito es producto de condiciones estructurales propias de la sociedad y no de desajustes individuales. La experiencia demuestra que la elevación del nivel de vida de la población, junto al incremento de las oportunidades de empleo y de capacitación y la distribución más adecuada del ingreso, entre otros factores contribuyen al mejoramiento de los indicadores delictivos"

En este período, se crea mediante decreto No. 241 del 11 de febrero de 1970, la hoy conocida Dirección de Prevención del Delito dependiente del Ministerio del Poder Popular para las Relaciones Interiores y de Justicia - precursora de la Comisión de Prevención de la Delincuencia, como organismo dependiente del Ministerio de Justiciaorganismo éste encargado de investigar las causas de la criminalidad en el país desde 1951- como sujeto planificador de la política antidelictiva en el país, con las siguientes atribuciones:

“a) Realizar investigaciones psicosociales y criminológicas a fin de obtener diagnósticos de la realidad que permitan el diseño de un plan de profilaxis social.

b) Diseñar, ejecutar y evaluar programas a nivel informativo y formativo dirigido a los distintos sectores de la sociedad.

c) Capacitar el personal adecuado para aplicar medidas de prevención.

d) Centralizar las estadísticas criminales a nivel nacional.

e) Elaboración de proyectos de leyes relacionados con la política antidelictiva.

f) Representar al Estado en eventos nacionales e internacionales relacionados a la prevención del delito.

g) Aplicar medidas de Profilaxis Social.

h) Coordinar los planes oficiales relacionados con la prevención del delito.

i) Otras".

En este contexto, el V Plan de la Nación (1976-1980), consideraba como una prioridad:

"persistir en la necesidad de generar, como valor social permanente, una conciencia preventiva del delito en el país y de igual forma implantar controles preventivos y represivos del fenómeno delictivo, armónicos entre sí y más coherentes con la acción de instituciones encargadas de aspectos tales como la salud, la nutrición, la educación, la seguridad social, el empleo y la recreación.

Ampliar la prevención del delito en las principales ciudades del país, dando un especial énfasis a las áreas marginales, y preferencialmente a los grupos etarios que se encuentran en etapa de adolescencia y juventud...por cuanto ellos representan en la estructura geográfica del país el $65,5 \%$ del total de la población." 11

\footnotetext{
${ }^{9}$ MINISTERIO PARA EL PODER POPULAR PARA LA PLANIFICACIÓN Y DESARROLLO. En http://www.mpd.gob.ve/cordiplan/quees.htm. [visitado el 12-12-2009].

${ }^{10}$ BRAVO, "Obstáculos a la Prevención del Delito en Venezuela", cit. nota $n^{\circ} 8$, p. 5.

${ }^{11}$ BRAVO, "Obstáculos a la Prevención del Delito en Venezuela", cit. nota $n^{\circ}$ 8, p. 5.
} 
AÑEZ, María Alejandra; LEONTE, Pablo. "La política criminal en Venezuela. Especial referencia a la conflictividad social en torno al delito de secuestro".

Por esta época, ocurre en el país el aumento de los índices de criminalidad, sobre todo en ciudades de alta concentración urbana y alta concentración de renta, estando la intervención estatal dirigida primordialmente al incremento del número de los cuerpos policiales en el país, situación ésta que se vio agravada por la escasa formulación de políticas públicas de seguridad, la desarticulación de las instancias que componen el sistema de justicia, el retardo procesal que funciona como un estimulo a la impunidad, la falta de una legislación penal específica de control del delito organizado, entre otros factores. ${ }^{12}$ Por lo que el auge de la criminalidad se atribuye a la crisis, al mal funcionamiento de las instituciones y al uso excesivo de la violencia institucional para la resolución de los conflictos sociales y políticos. ${ }^{13}$

Para el período 1981-1985, el VI Plan asumiría como prioridades el hacinamiento carcelario y el mal funcionamiento del sistema de justicia, reseñando:

\begin{abstract}
"A fin de lograr la paz y la estabilidad social necesarias para alcanzar los objetivos y metas globales del Plan, será necesario reducir el índice delictivo nacional y el hacinamiento penitenciario, garantizar a las personas naturales y jurídicas la defensa de sus derechos y facilitar el cumplimiento de sus deberes a través de un servicio de administración de justicia oportuna y eficiente. Para ello será necesario: aplicar un amplio programa de prevención del delito que promueva la participación organizada de los diferentes miembros de la comunidad; propiciar que los medios de comunicación social destaquen en su contenido los valores positivos de la sociedad, intensificar la recreación y el uso creativo del tiempo libre en niños y jóvenes; estimular la investigación criminológica, propiciar una reforma del ordenamiento legal vigente sobre este asunto; y ampliar la problemática" 14
\end{abstract}

En los siguientes planes, salvo los cambios de retórica y algunas variaciones en cuanto al grado de precisión de las propuestas oficiales al examinar las condiciones favorables al crecimiento del delito, pocos cambios sustanciales pueden advertirse, en lo que respecta a la prevención, considerada como materia de seguridad y defensa social, aunque reconoce la situación al precisar que "el incremento de la violencia, la crisis de la administración de justicia y la inseguridad ciudadana constituyen problemas que están quebrantando el Estado de Derecho" "15

Al respecto, el gobierno elegido para el período 1995-1999, se planteó sentar las bases de un desarrollo sostenido en nuestro país, planteando tres acciones simultáneas que comprendían promover el consenso para la construcción compartida de un proyecto societario para el país, llevar a cabo una serie de cambios estratégicos que consoliden los procesos de transformación hacia un desarrollo generador de mayor bienestar y mejorar, desde el corto plazo, las condiciones de vida de la población, elevando los

12 PROGRAMA VENEZOLANO DE EDUCACIÓN-ACCIÓN EN DERECHOS HUMANOS (PROVEA): "Situación de los Derechos Humanos en Venezuela.", Informe Anual Años 2000-2001. Capitulo: Derecho a la Seguridad Ciudadana. Caracas-Venezuela. Grupo Ediprint, C.A. pp. 291-311.

13 BIRKBECK, Christopher y CRESPO, Freddy, "Legitimidad Institucional y Delincuencia en Venezuela.", Capitulo Criminológico, Volumen 37, No. 1 (2009), Instituto de Criminología Dra. Lolita Aniyar de Castro, Universidad del Zulia, Maracaibo, Venezuela, pp. 5-41.

${ }^{14}$ BRAVO, "Obstáculos a la Prevención del Delito en Venezuela", cit. nota n ${ }^{\circ}$, p. 6.

${ }^{15}$ BRAVO, "Obstáculos a la Prevención del Delito en Venezuela", cit. nota ${ }^{\circ}$ 8, p. 6. 
Polit. crim. Vol. 6, № 11 (Junio 2011), Art. 2, pp. 19 - 43.

[http://www.politicacriminal.cl/Vol_06/n_11/Vol6N11A2.pdf]

niveles de empleo y la calidad de los servicios y reduciendo las desigualdades notorias que existen en la sociedad venezolana. ${ }^{16}$

No obstante, la realidad evidenció un resquebrajamiento de las instituciones políticas económicas y familiares, como consecuencia de la decadencia económica, el acelerado incremento de la inflación, el crecimiento de la tasa de desempleo, la caída del salario, el aumento de la cesta básica, la devaluación de la moneda, entre otras manifestaciones económicas que significaron la inexistencia de canales que mantuvieran a los individuos integrados a los medios sociales para conseguir los fines socialmente impuestos, y así lograr satisfacer sus necesidades básicas, apartando el modelo familiar tradicional de padre y madre con predomino masculino y mujer ama de casa, el cual es sustituido por el incremento de mujeres dentro de la fuerza laboral capaces de mantener un hogar por sí solas y de parejas unidas de hecho, bajo un lazo débil que no genera una fuerte vinculación entre la pareja y entre esta y sus hijos. ${ }^{17}$

Desde el punto de vista jurídico, las reformas suscitadas durante este período al código penal, no pueden ser consideradas como sustanciales, pues dejan incólume su estructura y se limitan a modificar accidentalmente algunos tipos penales de acuerdo a un criterio empírico de política criminal, ante la preocupación por el aumento de la criminalidad, la aparición de nuevas formas delictivas y el incremento de la misma, pretendiendo utilizar las reformas como un instrumento de manipulación colectiva que tratar de mitigar el sentimiento de inseguridad, infundir confianza y hacer creer ilusoriamente que con la sola reforma de la ley penal se podía lograr una correcta profilaxia social. ${ }^{18}$

\subsection{La Política Criminal durante la última década de Período Democrático (1999 - 2009).}

Los cambios jurídicos en el área comienzan a generarse en el año 1998, cuando en el marco de un proceso latinoamericano de reformas en los sistemas judiciales, se aprueba un Código Orgánico Procesal Penal (COPP) cuyos principios ajustados a un nuevo modelo acusatorio y de humanización de la justicia serán fortalecidos con la promulgación de la CRBV en el año siguiente, ${ }^{19}$ en el cual Venezuela se proclamó como "Estado Democrático Social de Derecho y de Justicia, propugnando como valores de su ordenamiento jurídico -entre otros- la preeminencia de los derechos humanos y como fin esencial "la defensa y desarrollo de la persona y el respecto a su dignidad...la promoción de la prosperidad y bienestar del pueblo y la garantía del cumplimiento de los principios, derechos y deberes consagrados en la Constitución".

Luego de producida la reforma constitucional a través del proceso constituyente, se formularon las "Líneas Generales del Plan Nacional de Desarrollo Económico y Social de la Nación 2001-2007", primer plan de la nueva era constitucional bolivariana, dirigido a profundizar los cambios estructurales hacia la construcción de la nueva República, operativizado a través de cinco equilibrios -el económico, social, político, territorial e internacional-, y que en conjunto se cumplirían en dos etapas: la denominada Década de Plata (2001-2010) como período de transición o fase previa a la Década de Oro (2011-2020) etapa de consolidación de la revolución bolivariana.

\footnotetext{
${ }^{16}$ REPÚBLICA BOLIVARIANA DE VENEZUELA. IX Plan de la Nación. Período de Gobierno 19941999. En: http://www.mpd.gob.ve/ixplan/ixplan.htm. [visitado el 12-12-2009].

${ }^{17}$ BIRKBECK/CRESPO, "Legitimidad Institucional y Delincuencia”, cit. nota n 13, pp. 11, 21, 23.

${ }^{18}$ SOSA, Jorge, Teoría General de la Ley Penal. 2da. Edición, Caracas: Ediciones Liber, 2000, p. 99.

${ }^{19}$ NUÑEZ, "Política de Seguridad Ciudadana", cit. nota n 4. p. 350.
} 
AÑEZ, María Alejandra; LEONTE, Pablo. "La política criminal en Venezuela. Especial referencia a la conflictividad social en torno al delito de secuestro".

En este sentido, el equilibrio social sería el eje encargado de alcanzar la justicia social, respondiendo a las necesidades sociales equitativamente como nuevo orden y base material de la sociedad venezolana, para lo cual se propone "profundizar el desarrollo humano mediante la ampliación de las opciones de las personas, el ofrecimiento de mayores y mejores oportunidades efectivas de educación, salud, empleo, de ingresos, de organización social y de seguridad ciudadana". ${ }^{20}$

Para concretar este objetivo, se establecieron otros sub-objetivos entre los cuales figura primigeniamente el "garantizar el disfrute de los derechos sociales y de forma universal y equitativamente", lo que entre otras cosas supone, la seguridad ciudadana como condición necesaria para el desarrollo humano, garantizando la superación de situaciones de amenaza, vulnerabilidad o riesgo para la vida de las personas, sus propiedades, la paz y la convivencia pacífica. En este sentido, plantea como estrategia:

"El enfrentamiento de los índices de criminalidad, se asume como una política integral, que comprende por una parte, la reducción de las desigualdades sociales, el incremento del nivel de empleo y la atención a los grupos sociales relativamente más pobres $\mathrm{y}$, por la otra parte, una política específica para la prevención y combate de la criminalidad y la violencia.

Desde el punto de vista de la política específica para la prevención y combate del delito, y asegurar así la tranquilidad ciudadana, se plantea el fortalecimiento de la coordinación policial, con la creación del centro de coordinación de inteligencia, el incremento de la participación ciudadana en la prevención y control del delito, la modernización de los sistemas de protección policial de los ciudadanos y de los hogares" 21

Resulta claro de estos enunciados que, a pesar que la familia, la escuela y los medios de comunicación son mencionados dentro del concepto más general de "seguridad permanente", no hay nada dentro de las estrategias y las políticas específicas que tomen en cuenta estas instancias a nivel de un modelo preventivo. El modelo, por consiguiente, a diferencia de lo que ocurría con otros Planes de la Nación, desde 1958 hasta 1998, no sólo dedica poco espacio y desarrollo al concepto y a los planes de prevención del delito, sino que, antes que identificar áreas específicas de intervención de acuerdo a modalidades y tendencias delictivas, coloca como común denominador de la delincuencia, la desigualdad socioeconómica y plantea como estrategia fundamental el fortalecimiento y centralización de la policía como mecanismo de disuasión, para afrontar el control de la criminalidad. ${ }^{22}$ Esto ha traído como consecuencia una dispersión en materia de seguridad, al punto que:

"Las decisiones en materia de prevención de la criminalidad han resultado parceladas, entendiéndose fundamentalmente la función de prevención como la formación y capacitación de distintos grupos de la población en determinadas áreas: alcoholismo, drogadicción, autoprotección, seguridad vecinal, formación del voluntariado, información preventiva general, entre otros, a fines de que puedan propiciar un crecimiento armónico y ser agentes multiplicadores en materia

\footnotetext{
${ }^{20}$ REPÚBLICA BOLIVARIANA DE VENEZUELA. Líneas Generales del Plan de Desarrollo, cit. nota $\mathrm{n}^{\circ} 16, \mathrm{p} .91$.

${ }^{21}$ REPÚBLICA BOLIVARIANA DE VENEZUELA. Líneas Generales del Plan de Desarrollo, cit. nota $\mathrm{n}^{\circ} 16$, p. 99.

${ }^{22}$ GABALDON, “Criminalidad, Reacción Social y Política.”, cit. nota n², p. 75.
} 
Polit. crim. Vol. 6, № 11 (Junio 2011), Art. 2, pp. 19 - 43.

[http://www.politicacriminal.cl/Vol_06/n_11/Vol6N11A2.pdf]

preventiva. Los cambios no han sido generados, encontrándonos ante un sentido desbordamiento de la violencia, delincuencia e inseguridad, que se integran a la vida diaria del individuo como otro elemento frustrante que se le impone, hasta el punto de sentirse indefenso e impotente de hacer algo para detener su acción siendo susceptible de ser víctima de cualquier hecho delictivo". ${ }^{23}$

Sin embargo los índices de criminalidad seguían en aumento, la crisis que atravesaban los cuerpos policiales y los crecientes casos de violencia política, ponían en grave riesgo la gobernabilidad del país y el sistema democrático. La alta rotación de altos funcionarios públicos, y la proliferación de planes y programas de prevención de la criminalidad -con predominio de operativos y acciones intermitentes- que no se mantienen en el tiempo y no guardan solución de continuidad con propuestas anteriores, de carácter coyuntural y de corto plazo, siguen siendo las principales características de las políticas públicas en el país. ${ }^{24}$

Para el año 2003, el problema de la violencia en la sociedad venezolana es de tal magnitud, que el incremento de las cifras de criminalidad, especialmente en las tasas de homicidios y en el número de robos y secuestros, revela una creciente y peligrosa erosión del monopolio de la violencia legítima por parte del Estado venezolano. Además, la guerra librada contra el delito por los cuerpos policiales (nacionales, estadales y municipales), produce por lo menos un $18 \%$ del total de los homicidios registrados oficialmente, por lo que lejos de revertirse los índices de criminalidad, se alimenta un círculo perverso de mayor violencia, criminalidad e irrespeto al marco constitucional. En este sentido, plantea el Programa Venezolano para Educación-Acción en Derechos Humanos (PROVEA) que:

"La inestabilidad política, la creciente debilidad y deslegitimidad institucional, la preeminencia de una represión indiscriminada y de una elevada violencia policial, en lugar del desarrollo de políticas ajustadas a derecho y consistentes con los principios de prevención social y situacional, son algunos de los factores presentes en el incremento de las principales cifras de criminalidad en el ámbito nacional". ${ }^{25}$

Durante los años 2004, 2005 y 2006, los indicadores de violencia siguieron en aumento y no hubo cambios significativos en el manejo del problema por parte del Estado, sino que, por el contrario, se repitieron las políticas voluntaristas, antidemocráticas, inconstitucionales y violentas de control, en ausencia de políticas efectivas de prevención social. Los escasos proyectos y programas en materia de seguridad ciudadana siguen priorizando operaciones puntuales con concentración de esfuerzos

\footnotetext{
${ }^{23}$ VALDERRAMA, Elizabeth y MORALES, María Isabel, El Planeamiento de la Prevención del Delito Aqui y Ahora. Trabajo elaborado por la Dirección de Prevención del Delito del Ministerio de Justicia para ser presentado en el XI Seminario Anual de la Investigación del CENIPEC, 1997, p.6. Disponible en: http://www.saber.ula.ve/bitstream/123456789/23597/1/articulo1.pdf. [visitado el 12-12-2009].

24 PROGRAMA VENEZOLANO DE EDUCACIÓN-ACCIÓN EN DERECHOS HUMANOS (PROVEA), Situación de los Derechos Humanos en Venezuela. Informe Anual, Años 2001-2002. Capitulo: Derecho a la Seguridad Ciudadana. Caracas-Venezuela. Grupo Ediprint, C.A. Disponible en: http://www.derechos.org.ve/proveaweb/wpcontent/uploads/006_derecho_a_la_seguridad_ciudadana.pdf. [visitado el 01-12-2009].

PROGRAMA VENEZOLANO DE EDUCACIÓN-ACCIÓN EN DERECHOS HUMANOS (PROVEA), Situación de los Derechos Humanos en Venezuela. Informe Anual, Años 2002-2003. Capitulo: Derecho a la Seguridad Ciudadana. Caracas-Venezuela. Grupo Ediprint, C.A., pp. 347-372.
} 
AÑEZ, María Alejandra; LEONTE, Pablo. "La política criminal en Venezuela. Especial referencia a la conflictividad social en torno al delito de secuestro".

fundamentalmente en el área represiva con participación predominante de los funcionarios de los cuerpos de seguridad del Estado. ${ }^{26}$

El presente y futuro de la política criminal en Venezuela, según los lineamientos generales del plan de desarrollo económico y social de la nación para el período 20072013, bajo el enfoque de su nueva ética socialista y la refundación de la nación, parece haber quedado en el aire, pues este documento ni siquiera se hace mención al problema delictivo, por lo que su plan de acción va guiado solo a crear una sólida arquitectura de valores sociales para "transformar la sociedad material y espiritualmente", con "justicia y equidad sin mirar las bases del derecho", creando un país en el que "la suprema felicidad social" este dada por la estructuración de "una nueva sociedad de incluidos", con un "nuevo modelo social, productivo, socialista, humanista, endógeno, donde todos vivamos en similares condiciones".

Todo esto hace presumir que -dadas estas condiciones- desde el pasado año 2007 la delincuencia debió haber sido sustancialmente disminuida en la sociedad venezolana, pues en un país en igualdad de oportunidades, donde todos los ciudadanos se sienten y efectivamente estén incluidos en el orden social, político y económico, debería haber menor incidencia de la criminalidad.

No obstante, lo cierto es que hasta hoy en Venezuela no se ha aplicado una política criminal coherente, no existe programa político criminal observable, de allí las acciones tomadas al azar, el desorden, la improvisación y la inseguridad, la descoordinación entre los organismos competentes, la carencia de sustentación científica y la subjetividad de quienes se encargan de la política antidelictiva, apabullada solo con reformas y más reformas sin sentido de las leyes penales, llevadas por la pasión o conmoción del momento, nada aconsejables. Por ello, la solución está en la seriedad de las instituciones del Estado, el trabajo fuerte y constante, aplicación de estudios coherentes y sinceridad en todo ello.

El período 2000-2009, se ha caracterizado por ser el escenario de sucesivas reformas legislativas y la promulgación de textos legales dirigidos al control de la delincuencia y seguridad ciudadana. En efecto, durante este lapso la Asamblea Nacional o el Presidente de la República a través de leyes habilitantes, han puesto en vigencia -en un intento de incidir en la prevención de la violencia y la criminalidad - una gran variedad de cuerpos legales, entre los cuales se encuentran: Ley de Coordinación de Seguridad Ciudadana; Ley de los Órganos de Investigaciones Científicas, Penales y Criminalísticas; Ley para la Seguridad Ciudadana y el Desarme del Ciudadano; Ley contra la Delincuencia Organizada, reformas del Código Penal, puntuales y diversas modificaciones al Código Orgánico Procesal Penal, la Ley Orgánica del Servicio de Policía Nacional y del Cuerpo de Policía Nacional, la Ley contra el Secuestro y la Extorsión, entre otras.

26 PROGRAMA VENEZOLANO DE EDUCACIÓN-ACCIÓN EN DERECHOS HUMANOS (PROVEA), Situación de los Derechos Humanos en Venezuela. Informe Anual, Años 2004-2005. Capitulo: Derecho a la Seguridad Ciudadana. Caracas-Venezuela. Grupo Ediprint, C.A. Disponible en: http://www.derechos.org.ve/proveaweb/wp-content/uploads/05_seguridad_ciudadana.pdf. [visitado el 0112-2009]. PROGRAMA VENEZOLANO DE EDUCACIÓN-ACCIÓN EN DERECHOS HUMANOS (PROVEA), Situación de los Derechos Humanos en Venezuela. Informe Anual, Años 2005-2006. Capitulo: Derecho a la Seguridad Ciudadana. Caracas-Venezuela. Grupo Ediprint, C.A., pp. 331-350. 
Polit. crim. Vol. 6, № 11 (Junio 2011), Art. 2, pp. 19 - 43.

[http://www.politicacriminal.cl/Vol_06/n_11/Vol6N11A2.pdf]

No cabe duda que el Estado debe propender al mantenimiento del orden público y la paz social, pero la sanción punitiva no puede ser el único medio para lograrlo. La tendencia del Estado Venezolano, ha sido usar del derecho penal como bandera de la seguridad, pretendiendo emplearlo como medio para restablecer la confianza de los ciudadanos hacia las instituciones y hacia el derecho, aun cuando -siguiendo a Zaffaroni- ${ }^{27}$ la función del derecho penal de todo estado de derecho debe ser el ejercicio racional del poder punitivo, si el derecho penal no logra que el poder jurídico asuma esta función, lamentablemente habrá fracasado y con él habrá caído el estado de derecho.

En materia de proyectos y programas en materia de seguridad ciudadana, pocos han sido los planes formulados y su ejecución se ha visto mermada por la alta rotación de la administración ministerial, además de reseñarse un predominio de operativos y acciones a corto plazo, sobre todo en fechas de alta rotación de población (durante los asuetos de carnaval, semana santa y navidad, entre otros), con predominante participación de efectivos militares. Algunos de los planes anunciados en esta materia han sido: el Plan Estratégico de Prevención de la Violencia y la Consolidación de la Convivencia Ciudadana 2001-2003, el Plan Bratton de la Alcaldía Mayor, Plan de Seguridad Ciudadana, Plan Nacional de Seguridad, el Método Link y la Misión Desarme de la Policía Estadal de Miranda, Redes Vecinales de Seguridad de la Alcaldía Metropolitana, Estrategia Nacional de Convivencia y Seguridad Ciudadana, Plan Caracas Segura, la instalación del Consejo Nacional de Seguridad, Plan Nacional Integral de Prevención y Seguridad Ciudadana, se creó el Consejo Nacional de Prevención y Seguridad Ciudadana y el Consejo General de Policías, ${ }^{28}$ y más recientemente el Dispositivo Bicentenario de Seguridad, dirigido prioritariamente a los diez estados que concentran el $60 \%$ de la población venezolana y que representan el $75 \%$ de los delitos del país, incluidas las ciudades de Caracas, Los Teques, Maracay, San Cristóbal, Maracaibo, Puerto La Cruz, Barcelona, Ciudad Bolívar y Barquisimeto. ${ }^{29}$

No obstante, se trata de intervenciones a corto plazo, que responden a las percepciones e inquietudes de la población sin mayor incidencia en las necesidades y nudos neurálgicos de la situación, además de estar escasamente articuladas entre sí o respecto a un programa o plan de mayor alcance que inserte los esfuerzos en una dinámica que permita obtener resultados, impactos positivos y colaborar decididamente en la conformación de una nueva situación progresivamente más parecida a la que se perfila como deseada. ${ }^{30}$ Respecto del sistema de justicia penal, se profundiza la crisis institucional afectando gravemente el derecho de acceso a la justicia que genera situaciones colaterales como la impunidad y el aumento de la cifra negra del delito, pues como acertadamente señalo Beccaria en su tiempo, la efectividad de la pena no está en su severidad sino en la prontitud y certeza de su aplicación.

\footnotetext{
${ }^{27}$ ZAFFARONI, Eugenio, El Enemigo en el Derecho Penal, Buenos Aires: Sociedad Anónima Editora Comercial, Industrial y Financiera, 2006, p. 169.

${ }^{28}$ Para este desglose se tomo como fuente de información la recogida por PROVEA en sus informes anuales publicados desde el año 2002 al 2009.

29 ROJAS, Edwin, "Dispositivo Bicentenario de Seguridad arrancará en marzo", Ministerio del Poder Popular para la Comunicación e Información, Caracas, Venezuela. 09-02-2010. Disponible en: http://www.minci.gob.ve/notivias/1/196004/dispositivo_bicentenario_de.html. [visitado el 02-03-2010]

${ }^{30}$ PROVEA, Situación de los Derechos Humanos en Venezuela, años 2005-2006, cit. nota ${ }^{\circ} 27$.
} 
AÑEZ, María Alejandra; LEONTE, Pablo. "La política criminal en Venezuela. Especial referencia a la conflictividad social en torno al delito de secuestro".

Es de notar, que el sistema penal en Venezuela no escapa -siguiendo a Baratta- ${ }^{31}$ de las disfuncionalidades que caracterizan en general a la justicia penal, toda vez que se ha inclinado a favorecer la represión por encima de la prevención -opera cuando las consecuencias de las infracciones ya se han producido y no para evitarlas-, interviene en los resultados de los conflictos sociales y no en sus causas, actúa sobre los individuos y no sobre las situaciones y, en fin, protege más que a las víctimas reales y potenciales, la validez de las normas.

En materia de participación comunitaria, ha venido trabajando el gobierno desde hace varios años. ${ }^{32}$ Ya desde el marco brindado por la constitución de 1999, se formula la necesidad de la participación ciudadana en los programas destinados a la prevención y seguridad ciudadana, siendo un derecho político fundamental del pueblo venezolano, su protagonismo en la formación, ejecución y control de la gestión pública.

Esta cuestión, fue legalizada con la escueta regulación del artículo 28 del decreto con rango y fuerza de Ley de Coordinación de Seguridad Ciudadana, que prevé la organización de la ciudadanía en la planeación y control de las políticas públicas en el ámbito de la seguridad ciudadana, derecho que además es enfatizado en la Ley Orgánica del Servicio de Policía y del Cuerpo de Policía Nacional, a través de la intervención del servicio de policía comunal ${ }^{33}$ y los consejos comunales, no solo en la planeación y gestión de la seguridad sino además como mecanismo de contraloría social sobre el servicio de policía.

Este marco normativo parece querer ser reforzado con la intencionalidad de presentar ante la Asamblea Nacional, un proyecto de Ley para la Promoción y Participación Ciudadana en materia de Prevención del Delito, en el que se regula el deber de las comunidades de incorporarse de manera organizada, con un sustento legal y políticas de estímulo en materia de prevención del delito. ${ }^{34}$

\footnotetext{
${ }^{31}$ BARATTA, Alessandro, "Política Criminal: entre la Política de Seguridad y la Política Social.", en: Delito y Seguridad de los habitantes. Compilado por CARRANZA, Elías, D.F., México: Siglo XXI Editores, 1997, pp. 158-159.

${ }^{32}$ Anterior a este período de gobierno, ya se habían suscitados experiencias en materia de participación ciudadana, a través de la creación en el Estado Zulia, de tres instancias en particular: el Consejo Regional de Seguridad, los Comités Locales de Seguridad y los Comités Vecinales de Seguridad. En cada una de ellas, confluían los actores políticos del Estado, las llamadas "fuerzas vivas de la sociedad" y la comunidad organizada, con la finalidad de coordinar acciones globales, diseñar estrategias basadas en las distintas experiencias de sus integrantes y evaluar resultados (Aniyar, 1999:22-23). Otra investigación más reciente llevada a cabo por equipo de investigación en el Municipio Maracaibo del Estado Zulia, reflejan como la intervención de la ciudadanía en la prevención del delito, provine de un acercamiento de la Policía Municipal y Regional hacia la comunidad -y no en inverso- principalmente a través de programas educativos y de incentivos hacia la participación. A nivel estadal un incipiente intervención comunitaria se evidenció con la creación de la Secretaria de Promoción y Prevención Ciudadana en el año 2001, a través de la cual se establecieron programas de atención a las comunidades que incluían la conformación de Comités de Defensa y Seguridad Ciudadana, la organización de guardianes juveniles y otros programas dirigidos a la escuela, el bienestar social y al deporte (Han y Col., 2008).

33 Para Aniyar (1999), la policía comunitaria, es más una Teoría Policíaca que una Teoría de la Participación, es una revisión que se hace la policía de sí misma, tratando de disminuir su papel autoritario y represivo, lo que sin duda constituye "un avance sobre el modelo profesional, y reposa sobre un cierto grado de participación, no representa aún un modelo totalmente social, y su éxito dependerá de la formación de los agentes policiales; así como del grado de penetración en ellos, y en los jefes de Departamentos Policiales, de la cultura corporativa.

${ }^{34}$ ROJAS, "Dispositivo Bicentenario de Seguridad", cit. nota ${ }^{\circ} 29$.
} 
Polit. crim. Vol. 6, № 11 (Junio 2011), Art. 2, pp. 19 - 43.

[http://www.politicacriminal.cl/Vol_06/n_11/Vol6N11A2.pdf]

No obstante, la realidad plantea otro escenario, la participación ciudadana, aunque es mencionada como elemento crucial para el éxito de las intervenciones en materia de seguridad, suele quedarse en lo meramente declarativo, ya que se la limita a la denuncia o a cubrir de manera privilegiada la figura del informante clave que suministra datos a la policía, insistiendo en la práctica, en propuestas que privilegian las soluciones de control y de fuerza, con el aumento de policía, de la Guardia Nacional, vigilantes públicos y privados, guardianes de la ciudad, policías de los barrios, etc., a esta situación, se suma la reserva gubernamental en proporcionar datos precisos acerca de la realidad del problema de la inseguridad en el país, pues no es posible entablar un debate público para el diseño, ejecución y evaluación de una política de seguridad ciudadana sin un criterio de transparencia que permita caracterizar la criminalidad y la violencia y ejercer acciones tendentes a su prevención y control. ${ }^{35}$

Lo cierto es que, una política criminal coherente y estructurada no se compone solo de un marco normativo que le de sustento, no se trata de abundar en normas simbólicas, repetitivas y represivas, sino primordialmente de ejercer acciones globales y coordinadas -tanto en relación con los actores sociales como respecto al resto de las políticas públicas del Estado- enfocadas hacia la modificación de las dimensiones objetivas y subjetivas de la criminalidad en el país, es decir, mejorar la calidad de vida del ciudadano estableciendo estrategias que no solo supriman la sensación de inseguridad, sino que además se perciba en cifras reales.

\section{Evolución del Delito de Secuestro en Venezuela.}

En Venezuela, el 27 de septiembre de 1961, se sucede el primer delito de secuestro cuando el avión de Avensa que cubría el vuelo No. 519 con destino Maracaibo-Caracas, es obligado por cinco sujetos armados a desviarse de su ruta y a sobrevolar la ciudad de Caracas. ${ }^{36}$ Sin embargo, dos años más tarde, en 1963, se registra el primer secuestro de personas, cuando un famoso futbolista argentino, Alfredo Di Stéfano, fue secuestrado el 24 de agosto en un hotel de San Bernardino - Caracas- por el grupo revolucionario denominado Fuerzas Armadas de Liberación Nacional (FALN), por razones políticas, siendo liberado tan solo tres días después, obteniendo con ello gran despliegue publicitario a nivel nacional e internacional. Sin embargo, según una estadística que recoge la Federación Nacional de Ganaderos de Venezuela (FEDENAGA), señala que fue en 1963 cuando se realizaron los tres primeros secuestros por dinero. ${ }^{37}$

Otros famosos secuestros, sacudieron para ese entonces al país. En 1963 el Coronel James Chenault, miembro de la misión militar norteamericana en Caracas y, once meses después, otro coronel de los Estados Unidos de América, Michael Smolen. En 1966 el secuestro seguido de la muerte de Julio Iribarren Borges, entonces Presidente del Seguro Social; en el año 1970 el secuestro del niño Johnny Fischback y el conmocionado caso del niño Carlos Vicente Vegas Pérez, en 1976 el del señor William Frank Niehous, vicepresidente de la empresa Owens Illinios de Venezuela, realizado en

\footnotetext{
${ }^{35}$ Así lo revelan los informes publicados por PROVEA durante los años 2004 al 2008.

${ }^{36}$ BUROZ, René, Secuestro. Ponencia presentada a la XIX Conferencia Interamericana de Abogados en Cartagena-Colombia. Editorial El Cojo, C.A. Caracas, Venezuela. 1975. p. 3.

${ }^{37}$ ULTIMAS NOTICIAS, 2008, "Secuestro: Un negocio de Nunca Acabar". Caracas, Venezuela. 13-042008. En: http://www.guia.com.e/noticias/?id=21271. [visitado el 09-02-2009].
} 
AÑEZ, María Alejandra; LEONTE, Pablo. "La política criminal en Venezuela. Especial referencia a la conflictividad social en torno al delito de secuestro".

Caracas $^{38}$ y el de Alfredo Pardi Dávila y Ricardo López Sánchez, en el estado de Zulia ese mismo año. ${ }^{39}$

Entre 1976 y 1999, 261 secuestros fueron denunciados en Venezuela, siendo los Estados con mayor incidencia Apure, Táchira, Zulia y Barinas, ${ }^{40}$ inicialmente los gremios afectados fueron los ganaderos y productores y los secuestros se realizaban muy cerca de las haciendas; más tarde se efectuaron en los lugares de trabajo, y ahora se secuestra hasta en las propias casas, con estrategias bien preparadas. ${ }^{41}$

Sólo hasta el año 2006, es posible tener acceso a las estadísticas publicas oficiales, cuyos datos procesadas por el Instituto Nacional de Estadísticas, tomando como fuente la información suministrada por el Ministerio de Interior y de Justicia, dan cuenta de que durante el período 2000-2006, se registraron 1329 casos de secuestro, teniendo como los cinco estados con mayor índice delictivo en materia de secuestros al Distrito Capital, seguido de Zulia, Táchira, Barinas y Carabobo.

Según la Encuesta Nacional de Victimización realizada en el 2006, el secuestro estaba entre los 10 delitos más frecuentes, con una tasa de 38,2/100.000, representando el $0,4 \%$ de la victimización total, ocupando la figura masculina en el $100 \%$ de los casos la víctima, probablemente porque en la mayoría de los casos estos son identificados como blancos atractivos, con un más alto nivel de interacción con los victimarios y mayor propensión a interactuar en situaciones de índole violenta. En cuanto al nivel socioeconómico, se observa un dato curioso, y es que los secuestros afectan fundamentalmente a los estratos III y IV de la población -es decir, a los incluidos en la clase media baja y en la clase pobre- lo cual sugiere que esta forma delictiva, no responde al estereotipo de figura emblemática de victimización para los sectores más pudientes de la población. ${ }^{42}$

La reciente Encuesta Nacional de Victimización y Percepción de Seguridad Ciudadana $2009,{ }^{43}$ realizada por el gobierno nacional, muestra como el secuestro sigue siendo uno de los diez delitos de mayor frecuencia en el territorio nacional-ocupando el séptimo lugar luego del robo, hurto, amenaza, lesiones personales, estafa y corrupción- con una tasa de 95,48 por cada 100.000 habitantes, representando esto el $1,14 \%$ de la victimización total a nivel nacional.

En estos tiempos prácticamente cualquier persona puede ser víctima de un secuestro, desde personas situadas en la cúspide social y política -líderes políticos, industriales, banqueros, profesionales, productores agropecuarios, sus esposas(os), hijos, familiares directos y/o políticos- trabajadores, niños, estudiantes y hasta amas de casa, todos pueden ser protagonistas y víctimas de esta impactante experiencia, con la condición de que sus victimarios crean que son capaces de pagar por vivir.

\footnotetext{
${ }^{38}$ BUROZ, Secuestro, cit. nota $\mathrm{n}^{\circ} 36$, p. 5.

${ }^{39}$ FUNDACIÓN PAÍS LIBRE. Antecedentes del Secuestro en el Mundo. Bogotá, Colombia. 1999. En: http://www.secuestro.freeserves.com/antecedentes.htm. [visitado el 09-02-2009].

40 NUÑEZ, Enrique, Los Delitos de Hurto, Robo, Espigamiento Abusivo, Extorsión y Secuestro. Caracas: Ediciones Librería Destino, 2001, pp. 229-247.

${ }^{41}$ FUNDACIÓN PAÍS LIBRE. Antecedentes del Secuestro, cit. nota ${ }^{\circ} 39$.

${ }^{42}$ GABALDON, “Criminalidad, Reacción Social y Política.", cit. nota n 2, pp. 69-70.

43 INSTITUTO NACIONAL DE ESTADÍSTICA, Encuesta Nacional de Victimización y Percepción de Seguridad Ciudadana 2009. Caracas, Venezuela, 2010, pp. 67-75.
} 
Polit. crim. Vol. 6, № 11 (Junio 2011), Art. 2, pp. 19 - 43.

[http://www.politicacriminal.cl/Vol_06/n_11/Vol6N11A2.pdf]

La precitada encuesta nacional señala que en el 74,34\% de los casos la víctima es de sexo masculino, en edades comprendidas entre los 25 y 44 años $(44,43 \%)$, pertenecientes a la clase social media alta (estrato social II), media baja (estrato social III) y pobre (estrato social IV) principalmente, con un porcentaje de ocurrencia de $27,97,19,94$ y 50,10 respectivamente, lo que mantiene la tendencia reseñada en la encuesta nacional de victimización realizada en el año 2006.

No cabe duda que la criminalidad evoluciona a la par del cambio y del desarrollo de la sociedad de la cual es producto, así, el delito refleja en buena parte -de acuerdo a la escuela positivista - el ritmo evolutivo cultural de toda sociedad, de modo que, a mayor cultura y desarrollo de la tecnología, el delito, en consecuencia, presentará variaciones cualitativas y cuantitativas, ${ }^{44}$ por lo que hoy día el secuestro, más que una estrategia para conseguir objetivos políticos, ideológicos o religiosos, como se concebía originalmente, ha pasado a convertirse en una estrategia muy lucrativa y rentable para organizaciones delictivas. El secuestro, de ser un delito característico de las zonas rurales, ha ido trasladándose a las ciudades, por lo que de ser los ganaderos las víctimas principales del mismo -hace aproximadamente 10 años- ahora la mayoría de los plagiados son estudiantes $(33 \%)$, comerciantes $(22 \%)$ y profesionales de diversas áreas $(12,5 \%)^{45}$

A nivel nacional, el Instituto Nacional de Estadísticas, ${ }^{46}$ detalla en función de las variables estudiadas para el delito de secuestro, que en el $76,95 \%$ este hecho punible es perpetrado por el hampa común, en un $15,74 \%$ es llevado a cabo por bandas delictivas $\mathrm{y}$, solo en un $1,87 \%$ es planificado y/o intervienen autoridades policiales. El delito generalmente es ejecutado en cualquier hora del día con una mayor tendencia entre las $6: 00$ y 12.00 de la noche $(46,50 \%)$, en su propio barrio o urbanización $(38,50 \%)$, empleando como medio de coacción la utilización de armas de fuego $(79,15 \%$ de los casos).

La mayoría de los casos reportados conducen a calificar el secuestro como breve o exprés, pues en un 73,41\% solo permanecen durante horas en cautiverio; no obstante, en los casos de secuestro extorsivo, el período en que la víctima permanece retenida puede oscilar entre un día $(9,25 \%)$, una semana ó dos semanas $(12,23 \%)$ o meses, pero sin sobrepasar el lapso de un año $(5,11 \%)$.

En Venezuela, un secuestro bien planificado, tiene un $90 \%$ de posibilidades de éxito, calculándose para el año 2008, que entre 300 y 500 mil dólares se exigía como cifra de rescate para altos ejecutivos y ganaderos. ${ }^{47}$ Datos más recientes extraídos de las sentencias registradas en el portal web del Tribunal Supremo de Justicia, muestran como los montos solicitados por los captores por concepto de rescate -por lo menos para iniciar las negociaciones- puede alcanzar la suma hasta de 1.000 millones de bolívares (equivalentes a un millón de bolívares fuertes), mientras que la cifra en dólares oscila entre los 4.5 y 6 millones.

\footnotetext{
${ }^{44}$ FLORES, Carmelo, Lecciones de Criminología. $3^{\text {a }}$ Ed., Caracas: Vadell Editores, 2007, pp. 43-96.

${ }^{45}$ EL NACIONAL, "Secuestros aumentaron 52\% el año pasado", Caracas, Venezuela. 09-01-2009. En: http://www.guia.com.ve/noticias/?id=33677.[visitado el 09-09-2009].

${ }^{46}$ INSTITUTO NACIONAL DE ESTADÍSTICA, Encuesta Nacional de Victimización y Percepción de Seguridad Ciudadana 2009, cit. nota ${ }^{\circ} 43$, p. 207.

47 CARRERA, Ernesto, “Cuánto cuesta un Secuestro?”, Diario Tal Cual, Caracas, Venezuela. 27-022008. En: www.guia.com.ve/noti/..(cuanto-cuesta-un-secuestro. [visitado el 01-12-2009].
} 
AÑEZ, María Alejandra; LEONTE, Pablo. "La política criminal en Venezuela. Especial referencia a la conflictividad social en torno al delito de secuestro".

Aunque los resultados de la encuesta nacional de victimización y percepción de seguridad ciudadana 2009 refieren que en la mayoría de los casos la víctima afirma no haber pagado para su liberación $(69,25 \%)$-bien porque los secuestradores desistieron del acto delictivo, por haber sido la víctima liberada antes de efectuarse el pago, y otros por existir confianza en la labor de las autoridades o por haber impedido la policía la materialización del pago- en aquellos casos en los que si se efectuó el pago el mismo osciló entre los 10.000 y 100.000 bolívares fuertes. ${ }^{48}$ Sin embargo un cruce de la información aportada por este informe, tal y como se refirió anteriormente, señala que la generalidad de las víctimas solo estuvo un día en cautiverio, por lo que el pago de esta suma correspondería al rescate negociado en un alto porcentaje en los secuestros exprés.

Esto lleva a afirmar que, el delito de secuestro en Venezuela ha cambiado notablemente sus patrones, de ser un delito predominantemente político, fronterizo y ejecutado por grupos organizados, ha pasado a ser un delito de objetivos principalmente económicos, urbano y desarrollado con un fin de lucro por la delincuencia común, al verse como un delito de grandes ganancias y relativamente poco riesgo.

\section{Política Criminal Antisecuestro en Venezuela.}

De una revisión de la política antisecuestro en Venezuela, resulta un vacio documental, y escuetas aristas que permitan hacer un diagnóstico sobre el asunto; el acceso a las fuentes oficiales es restringido, y los lineamientos existentes se desprende principalmente de la actividad legislativa desplegada por la Asamblea Nacional en su función de promulgar leyes que tiendan a la lucha contra este flagelo y de actividades operativas desarrolladas por los cuerpos de seguridad encargados de las tácticas antisecuestro.

A nivel jurídico, desde su establecimiento como delito autónomo en el Código Penal de 1897 (con una pena de presidio de tres a ocho años), pasando por las reformas de 1901, 1912 (que aumenta la pena de presidio de cuatro a nueve años), la de 1915 y la del año 1964 (que nuevamente incrementa la pena de presidio de diez a veinte años), la intervención legislativa en materia de secuestros fundamentalmente ha consistido en modificaciones cuánticas de la pena, procurando con estos cambios una mayor intimidación del individuo ante las consecuencias jurídicas del delito.

La regulación del código penal se mantuvo incólume incluso en el año 2000, cuando en el marco de las reformas legislativas se promulga un nuevo código penal, conservando el delito de secuestro el mismo tenor a lo establecido en el artículo 462 del código de 1964. Es con la última reforma del código penal efectuada en el año 2005, donde se modifica este artículo incluyendo una amplia gama de supuestos de hecho.

En ese mismo año, la Asamblea Nacional promulga la Ley Orgánica contra la Delincuencia Organizada, considerando al secuestro como un delito de delincuencia organizada y por tanto incluido en la tipificación de los tipos previstos en ese cuerpo normativo. No obstante, esto creo un problema de sobre-tipificación, al estar contenidas

${ }^{48}$ INSTITUTO NACIONAL DE ESTADÍSTICA, Encuesta Nacional de Victimización y Percepción de Seguridad Ciudadana 2009, cit. nota ${ }^{\circ} 43$, p. 208. 
Polit. crim. Vol. 6, № 11 (Junio 2011), Art. 2, pp. 19 - 43.

[http://www.politicacriminal.cl/Vol_06/n_11/Vol6N11A2.pdf]

en una ley ordinaria -código penal-y en una ley especial de carácter orgánica -ley orgánica contra la delincuencia organizada- una distinta tipificación (sujeto pasivo, el sujeto activo, los medios de comisión, los propósitos delictivos y el elemento de espacialidad) y penalidad para el mismo delito.

A lo largo de la historia, mucho se hablo sobre la necesidad de un texto legislativo especial en materia de secuestro. En efecto, en el año 2002 desde la Comisión Permanente de Defensa y Seguridad de la Asamblea Nacional, un grupo de parlamentarios, en su mayoría representantes de los estados fronterizos -integrantes de la Subcomisión de Seguridad Fronteriza- impulsaron la elaboración de un Anteproyecto de Ley Contra El Secuestro y la Extorsión (en lo adelante LCSYE), contentiva de 28 artículos, siendo aprobado en el mes de abril de $2003 .{ }^{49}$

Sin embargo no es hasta el mes de marzo año 2008, cuando la magnitud del problema lleva a una comisión especial de la Asamblea Nacional, a iniciar la discusión formal de la LCSYE mediante la aprobación de la estructura general y los cinco primeros artículos del texto legal, ${ }^{50}$ siendo finalmente aprobado el proyecto por la Comisión de Seguridad y Defensa del referido cuerpo legislativo en el mes de julio del mismo año, participando en su redacción, además de los diputados de la comisión, representantes del Ministerio del Poder Popular para Relaciones Interiores y Justicia, del Cuerpo de Investigaciones Científicas Penales y Criminalísticas (CICPC), del Ministerio Público, de la Defensoría del Pueblo, Tribunal Supremo de Justicia, Procuraduría General de la República, la Dirección de los Servicios de Inteligencia y Prevención (DISIP) y la Vicepresidencia de la República (Mundial Radio, 2008), que además incluyo un proceso de consulta, que en sus inicios abarco encuentros con las autoridades de los puestos militares, municipios, caseríos y parroquias de los estados fronterizos de la República, vale decir, Zulia, Táchira, Apure, Amazona y Bolívar; pasando luego, por un conjunto de mesas técnicas interinstitucionales y de alto nivel, resaltando además la participación popular en el marco de las Jornadas de Parlamentarismo Social de Calle llevado a efecto en el Palacio Federal legislativo en la ciudad de Caracas el 28 de julio del 2008. ${ }^{51}$

Finalmente, el 4 de junio de 2009, el Ejecutivo Nacional promulga la "Ley contra el Secuestro y la Extorsión", que se hace derecho positivo con su publicación en gaceta oficial el día 5 de junio del citado año, compilando un conjunto de normas especiales con el objeto de "prevenir, tipificar y sancionar los delitos de secuestro y extorsión y garantizar la protección de la integridad física de las víctimas y sus bienes", "bien sea contra ciudadanos y extranjeros que en ella se encuentren, o cuando sea ejecutado contra sus derechos, intereses o bienes, que se encuentren dentro o fuera del espacio geográfico de la República”. Este cuerpo normativo, establece siete tipos penales el tipo

\footnotetext{
${ }^{49}$ COMISIÓN PERMANENTE DE SEGURIDAD Y DEFENSA, Informe para Segunda Discusión Proyecto de Ley contra el Secuestro y la Extorsión. Asamblea Nacional de la República Bolivariana de Venezuela. 2008.

En: http://www.asambleanacional.gob.ve/index2.php?option=com_docman\&task=doc_view\&gid=795\&Itemi $\mathrm{d}=1$. [visitado el 20-12-2009].

50 AGENCIA BOLIVARIANA DE NOTICIAS, “Avanza Proyecto de Ley contra la Extorsión y el Secuestro.”, Caracas, Venezuela. 14-03-2008. En: http://www.aporrea.org/ddhh/n110830.html. [visitado el 01-12-2009].

${ }^{51}$ COMISIÓN PERMANENTE DE SEGURIDAD Y DEFENSA, Informe para Segunda Discusión, cit. nota $n^{\circ} 49$.
} 
AÑEZ, María Alejandra; LEONTE, Pablo. "La política criminal en Venezuela. Especial referencia a la conflictividad social en torno al delito de secuestro".

básico del secuestro, la simulación de secuestro, el secuestro con fines políticos, conmoción o alarma, secuestro breve, secuestro en medios de transporte, secuestro para canje de personas y el aislamiento forzoso.

No obstante, la LCSYE se constituye en una ley excesivamente represiva y desproporcionalmente punitiva, -considerando que la pena máxima en Venezuela según el mandato constitucional del artículo 44 numeral 3, es de treinta añosestableciendo penas hasta de treinta años en el tipo básico del secuestro e incluso hasta de veinticinco años en el caso del enriquecimiento ilícito provenientes de la perpetración de los delitos tipificados en la ley. Esto distorsiona todo los criterios de fijación de penas sostenidos en la doctrina penal, lo que en apariencia lleva a concluir que el legislador apuesta solo en la intimidación derivada de la severidad de las penas, la lucha contra este delito.

Esto, da la apariencia de que la ley es usada como proceso de inducción de la alarma social trasmitida por la opinión pública -sin soslayar la realidad en cifras que circunda este tipo delictivo- pues como bien lo plantea Baratta (2004), ${ }^{52}$ en ciertos momentos de crisis del sistema de poder los individuos son manipulados directamente por las fuerzas políticas interesadas, en el curso de las llamadas campañas de "ley y orden", pero que, independientemente de estas campañas limitadas en el tiempo, desenvuelven una acción permanente para la conservación del sistema de poder, oscureciendo la conciencia de clase y produciendo la falsa representación de una solidaridad que une a todos los ciudadanos en la lucha contra un común enemigo interno, es decir, se emplea -como siempre ha sido- la represión del delito como una bandera política que se ajusta a la clemencia popular de resguardo de la seguridad ciudadana.

Por su parte, con el auge delictivo en los casos de extorsión y secuestro, la Guardia Nacional activa el Grupo de Anti extorsión y Secuestro, inicialmente en los estados Táchira y Zulia, dependientes de los comandos regionales Nos. 1 y 3 respectivamente, como unidades especializadas con jurisdicción en la frontera con Colombia. No obstante, con el transcurrir del tiempo y el aumento de este tipo de delitos, se han activado estos grupos en el resto de los comandos regionales, siendo un total de nueve, con competencia en los estados Carabobo, Lara, Caracas, Miranda, Vargas, Apure, Guárico, Barinas, Anzoátegui, Bolívar, Delta Amacuro y el Estado Amazonas; con la finalidad de conducir en forma permanente operaciones de inteligencia e investigación penal para prevenir y combatir los delitos de extorsión y secuestro, organizar acciones que permitan la captura de los autores intelectuales y cómplices de este delito, además de poseer una alta capacidad para ejecutar operaciones especiales de rescate de rehenes y maniobras de apoyo táctico, ello con el objeto de garantizar la integridad personal del agraviado y la posesión legítima de sus pertenencias. ${ }^{53}$

En el año 2001 se había creado la División contra la Extorsión y Secuestro del CICPC, -sustituyendo la Brigada Antiextorsión de la División contra Robos, que hasta entonces se había ocupado de la investigación de estos tipos penales- con cobertura nacional,

52 BARATTA, Alessandro, Criminología Crítica y Crítica del Derecho Penal. Introducción a la Sociología Jurídico-Penal. $1^{\text {a }}$ Reimpresión. Buenos Aires: Siglo XXI Editores, 2004. pp. 209-222.

${ }^{53}$ GUARDIA NACIONAL, Directiva que regirá la actuación de la Guardia Nacional en la conducción de operaciones para el mantenimiento de orden interno ante la presencia de los delitos de secuestro y extorsión. 2003. En: http:/www.gp.cnti.ve/site/guardia.mil.ve/view/...directivaseguridadvial.doc. [visitado el 01-12-2009]. 
Polít. crim. Vol. 6, № 11 (Junio 2011), Art. 2, pp. 19 - 43.

[http://www.politicacriminal.cl/Vol_06/n_11/Vol6N11A2.pdf]

exceptuando Táchira, Zulia y Bolívar, por contar con sus propios equipos de trabajo en esta materia. En el caso de Táchira y Zulia, por registrar los mayores índices delictivos en extorsión y secuestro, y en el Estado Bolívar, por haberse creado por instrucción del comisario jefe Joel Rengifo. ${ }^{54}$

Esta División, adscrita a la Dirección de Investigaciones de Delitos contra el Patrimonio de la Coordinación Nacional de Investigaciones Penales del Cuerpo de Investigaciones Científicas, Penales y Criminalísticas (CICPC), tiene las siguientes funciones:

1. "Iniciar las averiguaciones por denuncia o noticia crímenes.

2. Realizar diligencias necesarias en la investigación criminal.

3. Planificar y realizar labores de inteligencia.

4. Investigar los casos tendentes a la localización de personas secuestradas.

5. Realizar negociaciones con los plagiarios cuando se ha cometido un secuestro.

6. Rescatar las personas que han sido secuestradas.

7. Realizar acciones preventivas con el propósito de proteger la vida de personas que han sido secuestradas.

8. Identificar plenamente al (los) autor (es) del hecho punible.

9. Instruir y sustanciar expedientes para su remisión a los organismos jurisdiccionales competentes.

10. Contribuir en la aprehensión de plagiarios en nuestro país.

11. Prestar apoyo técnico y especializado a todas las dependencias." 55

En este contexto, la Guardia Nacional, ${ }^{56}$ toma como acción de comando, la creación de la Patrulla "Pase Fénix" a nivel comando de destacamento y comando de compañía, unidad que además de cumplir con los servicios institucionales, ejercerá acciones que tiendan a reprimir el delito de secuestro y extorsión en la poligonal de patrullaje asignado bajo su responsabilidad, y la cual se corresponde con la jurisdicción de los referidos comandos. Al respecto esta unidad se planteó cuatro fases en su plan de acción, la primera dirigida a la prevención, la segunda a la reacción post delito, la tercera dirigida a ejercer acciones ante la amenazas concretas y la última fase dirigida a la producción de inteligencia a través de la búsqueda y procesamiento de información.

En relación concreta al delito de secuestro, la Organización de las Naciones Unidas, ${ }^{57}$ ha diseñado una especie de test o lista de comprobación, que permite a los Estados revisar la pertinencia de sus políticas nacionales en la lucha contra el secuestro, y así plantean el examen de los siguientes ítems:

- ¿Hay una política y estrategia nacional clara respecto del secuestro?

- ¿Hay un sistema nacional coherente para buscar, recoger y analizar información y evalúa continuamente la amenaza planteada por el secuestro?

\footnotetext{
${ }^{54}$ VARGAS, Mirtha, "Las Investigaciones de la División contra Extorsión y Secuestros.", Revista del CICPC. Caracas, Venezuela, pp. 182-185. En: http://revistacicpc.com/revistas/cicpc20/070.pdf. [visitado el 01-12-2009].

${ }^{55}$ Esta información puede ser consultada a través de la página http://www.cicpc.gov.ve/organigrama

${ }^{56}$ GUARDIA NACIONAL, Directiva que regirá la actuación, cit. nota n ${ }^{\circ} 53$, pp. 4-14.

${ }^{57}$ ORGANIZACIÓN DE LAS NACIONES UNIDAS, Manual de Lucha contra el Secuestro. Nueva York, 2006. En: http://www.mpf.gov.ar/../Manual-de-lucha-contra-el-secuestro-ONU.pdf. [visitado el 01-12-2004], p. 16.
} 
AÑEZ, María Alejandra; LEONTE, Pablo. "La política criminal en Venezuela. Especial referencia a la conflictividad social en torno al delito de secuestro".

- ¿Hay legislación nacional vigente para prevenir, disuadir y detectar el secuestro?

- ¿Tiene los organismos encargados de hacer cumplir la ley y las autoridades judiciales los poderes necesarios para enfrentar el secuestro?

- ¿Hay una respuesta operacional dotada de los recursos adecuados, capacitada y coordinada para responder en casos de secuestro?

- ¿Hay acuerdos vigentes para la coordinación nacional entre todos los organismos (Incluidos los sectores público y privado)?

- ¿Se ha establecido un punto focal nacional para la coordinaron y la acción a nivel internacional (y a nivel nacional)?

- ¿Son claras y se comprenden las responsabilidades de los diversos organismos y departamentos (gubernamentales)?

- ¿Se han ratificado y puesto en práctica todos los instrumentos jurídicos internacionales pertinentes para la aplicación de una estrategia eficaz para combatir el secuestro (véase el anexo I)?

- ¿Se cuenta con un proceso para examinar las cuestiones mencionadas Supra?

Una evaluación de estos aspectos esenciales de la política nacional antisecuestro que deben seguir los Estados para socavar el delito de secuestro y cumplir con su responsabilidad de mantener la seguridad, la paz y el orden en protección de los individuos y la prevención de la delincuencia, en Venezuela, revela la ineficacia gubernamental para afrontar el problema de la criminalidad con especial referencia al secuestro.

En efecto en Venezuela no existe -ni ha existido- una política ni estrategia clara y a largo plazo respecto del secuestro, no se conoce la magnitud del sistema de información nacional que permita retroalimentar la acción gubernamental en torno a este tema -pues ni siquiera se hacen públicas las cifras oficiales- la escases de recursos, la falta de coordinación entre los cuerpos de seguridad, la disputa entre los diversos organismos competentes, son algunos de las barreras con las cuales se enfrentan el Estado en su compleja y difícil tarea y a la vez constituye una ventaja para la delincuencia común y organizada.

Una política de prevención de este delito, requiere una comprensión del problema, es decir, comprender la dinámica del secuestro, dónde sucede, quién corre el riesgo, quiénes son los secuestradores, cómo operan y qué los motiva, esto requiere la puesta en práctica de una base de datos para reunir, recopilar, almacenar, analizar y difundir la información sobre el secuestro. Además es fundamental la coordinación entre las autoridades competentes en materia de secuestro y el sistema de justicia penal; la asignación de recursos, la capacitación del personal, la divulgación de programas educativos y de concientización, el apoyo de los medios de comunicación y, en general una participación de todos los sectores, incluyendo al sector público y privado. ${ }^{58}$

Como es de notar, la política criminal - preventiva y represiva- requiere del enlace de una serie de factores: recursos humanos, financieros, materiales y tecnológicos, capacitación, sistemas de información, legislación adecuada, respuesta oportuna de las

\footnotetext{
${ }^{58}$ ORGANIZACIÓN DE LAS NACIONES UNIDAS, Manual de Lucha contra el Secuestro, cit. nota ${ }^{\circ}$ 57, pp. 16-20.
} 
Polit. crim. Vol. 6, № 11 (Junio 2011), Art. 2, pp. 19 - 43.

[http://www.politicacriminal.cl/Vol_06/n_11/Vol6N11A2.pdf]

autoridades ejecutivas y del sistema judicial, atención a la víctima y a sus familiares, participación de todos los sectores, guiados por líneas de acción claras, específicas y coordinadas entre las diversas instancias de gobierno, de modo de aumentar los riesgos y disminuir las ventajas del delito para sus autores.

\section{Conclusiones.}

Ante el visible incremento de los índices de criminalidad, el justificado sentimiento de inseguridad por parte de la colectividad y la alarma social generada por el sensacionalismo noticioso, la tendencia gubernamental ha sido emplear una política criminal más represiva que preventiva, queriendo apaciguar el escenario con sucesivas reformas penales basadas en la creación de nuevos tipos y la modificación de otros, especialmente en la agravación de las penas, tanto en el código penal como por medio de leyes especiales. En efecto, la prevención parece dejarse casi exclusivamente en manos del sistema jurídico, mientras que la actuación de los cuerpos de seguridad inicia en el momento post-delictual.

Sin embargo la realidad parece mostrar como la teoría de prevención general ha fracaso, pues la sucesiva cadena de aumentos de penas en las reformas del código penal y aún con la puesta en vigencia de la ley contra el secuestro y la extorsión, no ha disminuido el impacto del secuestro como modalidad delictiva. Más aún, el referido instrumento legal se presenta como una iniciativa de buenas intenciones, incluso en sintonía con las medidas legales tomadas por otros países de América Latina, como es el caso de Colombia y México, pero cargada de un exacerbado punitismo retribucionista, en nada consonó con los fines resocializadores proclamados en la carta magna.

Esto sólo revela la importancia de considerar criterios de política criminal uniformes y coherentes con la realidad circundante al momento de estructurar y reformar el sistema penal de un país, de ahí que puede afirmarse que la política criminal es la guía que define los principios que rigen el derecho penal de un ordenamiento jurídico determinado, que debe basarse en sus elementos estructurales y no en crisis coyunturales del sistema, pues una política definida desde esta perspectiva, solo supone un ataque momentáneo del problema y no su solución -o por lo menos su control- a largo plazo.

No obstante, la desarticulación de los valores sociales, las condiciones políticas y económicas del país, la ausencia de políticas claras y definidas, la improvisación y anomalía en el proceso de creación de las leyes y con ello la falsa representación de un estamento normativo, dejar exclusivamente al basamento jurídico el control de la criminalidad, la imprecisión de cifras, la carente sistematización de información, el populismo, los problemas carcelarios, la excesiva dependencia (horizontal y vertical) de los poderes públicos respecto al ejecutivo nacional y la falta de coordinación entre los cuerpos de seguridad por razones eminentemente partidistas, la credibilidad de las instituciones; son solo algunos de los síntomas de la enfermedad que esta corroyendo las instituciones democráticas del Estado, mostrando que no existe remedio para el mal, pues no parecen estar dadas las condiciones para tener un efectivo control sobre el problema.

El captar y procesar información relevante al ámbito local, regional y nacional a través de un sistema de información único, es un paso importantísimo, toda vez que el registro, 
AÑEZ, María Alejandra; LEONTE, Pablo. "La política criminal en Venezuela. Especial referencia a la conflictividad social en torno al delito de secuestro".

análisis y generación de inteligencia operativa contra el secuestro, permitirá definir estrategias autenticas, coordinar investigaciones y en general maximizar la capacidad de los cuerpos de seguridad del estado, esto constituye una fuente de conocimiento certero para la definición de una política criminal a largo plazo de la mano del resto de las políticas públicas del país, para así no solo lograr la localización y rescate de las víctimas, sino además la desarticulación de las bandas delictivas que desarrollan esta actividad, pues la lucha contra el delito no se supera con la amenaza de una pena sino con acciones que hagan menos atractivo el delito, y es aquí donde la confianza hacia las instituciones juega un papel preponderante, pues acerca al ciudadano y debería tender a inhibir al delincuente.

Esto a su vez permitirá dar a conocer estadísticas oficiales más precisas a la colectividad, mostrando a la ciudadanía en una especie de contraloría social, las acciones emprendidas por el gobierno para combatir el secuestro, sus resultados y evaluaciones para establecer los correctivos, emprender nuevas estrategias y redefinir la política criminal. 
Polít. crim. Vol. 6, № 11 (Junio 2011), Art. 2, pp. 19 - 43.

[http://www.politicacriminal.cl/Vol_06/n_11/Vol6N11A2.pdf]

\section{REFERENCIAS BIBLIOGRÁFICAS}

AGENCIA BOLIVARIANA DE NOTICIAS, "Avanza Proyecto de Ley contra la Extorsión y el Secuestro". Caracas, Venezuela, 14-03-2008. En: http://www.aporrea.org/ddhh/n110830.html. [visitado el 01-12-2009].

ASAMBLEA NACIONAL CONSTITUYENTE, Código Penal. Caracas, Venezuela, Gaceta Oficial Extraordinaria No. 5.768 de fecha 13 de abril de 2005.

, Ley contra el Secuestro y la Extorsión. Caracas, Venezuela. Gaceta Oficial No. 39.194 de fecha 05 de septiembre de 2009.

Ley Orgánica contra la Delincuencia

Organizada. Caracas, Venezuela. Gaceta Oficial No. 38.281 de fecha 27 de septiembre de 2005.

BARATTA, Alessandro, "Política Criminal: entre la Política de Seguridad y la Política Social." En: Delito y Seguridad de los habitantes. Compilado por CARRANZA, Elías. D.F., México: Siglo XXI Editores, 1997, pp. 158-159.

, Criminología Crítica y Crítica del Derecho Penal. Introducción a la Sociología Jurídico-Penal. $1^{\text {a }}$ Reimpresión, Buenos Aires: Siglo XXI Editores, pp. 209-222.

BERISTAIN, Antonio, "Hoy y Mañana de la Política Criminal. Protectora y Promotora de los Valores Humanos". En: Política Criminal Comparada, Hoy y Mañana. Compilado por BERISTAIN, Antonio, Cuadernos de Derecho Judicial, Consejo General del Poder Judicial, Escuela Judicial. Madrid, España, 2009. pp. 11-85, pp.14-15.

BIRKBECK, Christopher y CRESPO, Freddy, "Legitimidad Institucional y Delincuencia en Venezuela." Capitulo Criminológico, Volumen 37, No. 1 (2009) Instituto de Criminología Dra. Lolita Aniyar de Castro, Universidad del Zulia, Maracaibo, Venezuela, pp. 5-41

BRAVO, Luis, Obstáculos a la Prevención del Delito en Venezuela. Ponencia presentada en el I Encuentro Anual de Criminología. Universidad de Los Andes, Mérida, Venezuela.2004. En: http://www.venecrim.com/pdf/OBSTACULOSALAPREVENCIONDELDELITO ENVENEZUELA.pdf. [visitado el 12-12-2009].

BUROZ, René, Secuestro, Ponencia presentada a la XIX Conferencia Interamericana de Abogados en Cartagena-Colombia. Caracas: Editorial El Cojo, C.A., 1975. p. 3.

CARRERA, Ernesto, “¿Cuánto cuesta un Secuestro?”, Diario Tal Cual, Caracas, Venezuela. 27-02-2008. En: www.guia.com.ve/noti/..(cuanto-cuesta-un-secuestro. [visitado el 01-12-2009].

COMISIÓN PERMANENTE DE SEGURIDAD Y DEFENSA, Informe para Segunda Discusión Proyecto de Ley contra el Secuestro y la Extorsión. Asamblea Nacional de la República Bolivariana de Venezuela, 2008. En: http://www.asambleanacional.gob.ve/index2.php?option=com_docman\&task $=$ doc _view\&gid=795\&Itemid=1. [visitado el 20-12-2009].

EL NĀCIONAL, "Secuestros aumentaron 52\% el año pasado", Caracas, Venezuela. 0901-2009, en: http://www.guia.com.ve/noticias/?id=33677. [visitado el 02-092009].

FLORES, Carmelo, Lecciones de Criminología, $3^{\text {a }}$ Ed. Caracas: Hermanos Vadell Editores, 2007, pp. 43-96. 
AÑEZ, María Alejandra; LEONTE, Pablo. "La política criminal en Venezuela. Especial referencia a la conflictividad social en torno al delito de secuestro".

FUNDACIÓN PAÍS LIBRE, Antecedentes del Secuestro en el Mundo, Bogotá, 1999. En: http://www.secuestro.freeserves.com/antecedentes.htm. [visitado el 09-022009].

GABALDON, Luis Gerardo, "Criminalidad, Reacción Social y Política: Una Visión en el Contexto de la Reforma Policial Venezolana.", Revista Relación Criminológica, Universidad de Carabobo, Segunda Etapa, No. 15, Segundo Semestre (2006), pp. 67-78.

GARCÍA, Sergio, "Reflexiones de Política Criminal.”, Criminalia, México Año LXII, $\mathrm{N}^{\circ}$ 2, (1997), pp. 93-101. En: http://www.bibliojuridica.org/libros/2/756/22.pdf. [visitado el 01-12-2009].

GUARDIA NACIONAL, Directiva que regirá la actuación de la Guardia Nacional en la conducción de operaciones para el mantenimiento de orden interno ante la presencia de los delitos de secuestro y extorsión. 2003. En: http://www.gp.cnti.ve/site/guardia.mil.ve/view/...directivaseguridadvial.doc. [visitado el 01-12-2009].

INSTITUTO NACIONAL DE ESTADÍSTICAS, Índice y Entorno del Desarrollo Humano en Venezuela 2001. Presidencia de la República Bolivariana de Venezuela. Programa de las Naciones Unidas para el Desarrollo. Fondo de Población de las Naciones Unidas. Caracas, Venezuela, 2002, pp. 123-140.

, Índice y Entorno del Desarrollo

Humano en Venezuela. Edición Especial 2002-2005. Presidencia de la República Bolivariana de Venezuela. Caracas, Venezuela, 2007. pp. 209-260.

, Índice y Entorno del Desarrollo

Humano en Venezuela 2006. Presidencia de la República Bolivariana de Venezuela. Coordinación de Publicaciones y Artes Gráficas de la Gerencia de Desarrollo de Productos, Gerencia General de Divulgación Estadística. Caracas, Venezuela, 2009, pp. 123-140.

Encuesta Nacional de Victimización y Percepción de Seguridad Ciudadana 2009. Caracas, Venezuela, 2010, pp. 67-75.

LARRANDART, Lucila, “Política Criminal y Estado de Derecho. ¿Tolerancia Cero?”, Capitulo Criminológico, Volumen 34, No. 2 (2006), Instituto de Criminología Dra. Lolita Aniyar de Castro, Universidad del Zulia, Maracaibo-Venezuela, pp. 161-200.

MARTINEZ, José, "Política Criminal, Terrorismo y Reforma Penal. El Caso Venezuela.", Revista CENIPEC, Vol. 25 (2006), pp. 321 - 341. Centro de Investigaciones Penales y Criminológicas Héctor Febres Cordero, Universidad de Los Andes, Facultad de Ciencias Jurídicas y Políticas, Mérida-Venezuela.

NUÑEZ, Enrique, Los Delitos de Hurto, Robo, Espigamiento Abusivo, Extorsión y Secuestro. Caracas: Ediciones Librería Destino, 2001, pp. 229-247.

NUÑEZ, Gilda, "Política de Seguridad Ciudadana en Venezuela. Especial Referencia al Desarrollo Jurídico Penal.", Capitulo Criminológico, Volumen 34, No. 3 (2004), Instituto de Criminología Dra. Lolita Aniyar de Castro, Universidad del Zulia, Maracaibo, Venezuela, pp. 339-361

ORGANIZACIÓN DE LAS NACIONES UNIDAS, Manual de Lucha contra el Secuestro. Nueva York, 2006. En: http://www.mpf.gov.ar/.../Manual-de-luchacontra-el-secuestro-ONU.pdf. [visitado el 01-12-2004], p. 16.

PROGRAMA VENEZOLANO DE EDUCACIÓN-ACCIÓN EN DERECHOS HUMANOS (PROVEA), Situación de los Derechos Humanos en Venezuela. 
Polít. crim. Vol. 6, № 11 (Junio 2011), Art. 2, pp. 19 - 43.

[http://www.politicacriminal.cl/Vol_06/n_11/Vol6N11A2.pdf]

Informe Anual. Años 2000-2001. Capitulo: Derecho a la Seguridad Ciudadana. Caracas: Grupo Ediprint, C.A. pp. 291-311.

, Situación de los Derechos Humanos en Venezuela.

Informe Anual. Años 2001-2002. Capitulo: Derecho a la Seguridad Ciudadana. Caracas: Grupo Ediprint, en: http://www.derechos.org.ve/proveaweb/wpcontent/uploads/006_derecho_a_la_se guridad_ciudadana.pdf. [visitado el 01-12-2009].

, Situación de los Derechos Humanos en Venezuela.

Informe Anual. Años 2002-2003. Capitulo: Derecho a la Seguridad Ciudadana. Caracas: Grupo Ediprint, C.A., pp. 347-372.

, Situación de los Derechos Humanos en Venezuela.

Informe Anual. Años 2004-2005. Capitulo: Derecho a la Seguridad Ciudadana. Caracas: Grupo Ediprint, C.A., en: http://www.derechos.org.ve/proveaweb/wpcontent/uploads/05_seguridad_ciudadana.pdf. [visitado el 01-12-2009]. , Situación de los Derechos Humanos en Venezuela.

Informe Anual. Años 2005-2006. Capitulo: Derecho a la Seguridad Ciudadana. Caracas: Grupo Ediprint, C.A., pp. 331-350.

REPÚBLICA BOLIVARIANA DE VENEZUELA, IX Plan de la Nación. Período de Gobierno 1994-1999. En: www.mpd.gob.ve/ixplan/ixplan.htm. [visitado el 12-122009]. http://www.mpd.gob.ve/pdeysn/plan.htm. [visitado el 12-12-2009]. http://www.gobiernoenlinea.ve/noticiasview/shareFile/lineas_generales_de_la_nacion.pdf. [visitado el 12-12-2009].

ROJAS, Edwin, "Dispositivo Bicentenario de Seguridad arrancará en marzo." Ministerio del Poder Popular para la Comunicación e Información. Caracas, Venezuela. 09-02-2010. En: http://www.minci.gob.ve/notivias/1/196004/dispositivo_bicentenario_de.html. [visitado el 02-03-2010]

SOSA, Jorge, Teoría General de la Ley Penal. 2a Ed., Caracas: Ediciones Liber, 2000, p. 99.

ULTIMAS NOTICIAS, 2008. "Secuestro: Un negocio de Nunca Acabar". Caracas, Venezuela. 13-04-2008. En: http://www.guia.com.ve/noticias/?id=21271. [visitado el 09-02-2009].

VALDERRAMA, Elizabeth y MORALES, María Isabel, El Planeamiento de la Prevención del Delito Aqui y Ahora. Trabajo elaborado por la Dirección de Prevención del Delito del Ministerio de Justicia para ser presentado en el XI Seminario Anual de la Investigación del CENIPEC, 1997, p. 6. En: http://www.saber.ula.ve/bitstream/123456789/23597/1/articulo1.pdf. [visitado el 12-12-2009].

VARGAS, Mirtha, "Las Investigaciones de la División contra Extorsión y Secuestros.", Revista del CICPC, Caracas, Venezuela. pp. 182-185. En: http://revistacicpc.com/revistas/cicpc20/070.pdf. [visitado el 01-12-2009].

ZAFFARONI, Eugenio, El Enemigo en el Derecho Penal. Buenos Aires: Sociedad Anónima Editora Comercial, Industrial y Financiera, 2006, p. 169. 